\title{
Mass schooling, empowerment, and demographic and economic outcomes: a note of dissent
}

\author{
Alaka Malwade Basu*
}

In this note, I use as a peg a recent publication by Lutz et al. (2009) because it summarises, develops and supports many of the main arguments for the policy focus on mass universal schooling that has become the mantra in development planning during the last quarter century or so. I also use this paper because it is so comprehensive, so clearly written and firm in its general conclusions even as it recognises that there is much more research to be done. But most of all, I use it because I wish I could have plagiarised the title of one of its references - an essay Lutz wrote and published as a 15 year old schoolboy - not only because it is a charming title but because it (the title, I don't have access to the actual essay) seems to say what I too want to say (albeit much more hesitantly than an impetuous schoolboy) in this cautionary note.

Lutz's boyhood essay was entitled "Elementary School: A Crime on Children". Before I make that lament the subject of my own essay here, there are some clarifications and caveats to underline what my short paper is not. It is not a rabble rouser's attempt to discredit the huge investments in public schooling toward which the international development community, including the international research community, has been pressurising national governments so as to make universal and compulsory primary schooling a national commitment, contrary to Lutz's (2009) apprehension. Goal 2 of the Millennium Development Goals - all children to complete a full course of primary schooling by 2015 - is only one natural outcome of the consensus that such a commitment will lead to a better world economically, socially and politically. I agree that acting on such a commitment will be a welcome first step, but that is all it can be - only a first step towards a much more ambitious agenda of giving everyone a much higher level of education than the four or five years that primary school requires.

I say this in spite of the evidence that the old adage - that a little learning is a dangerous thing - seems to be contradicted for most development outcomes. I concede that primary school attainment rates are strong predictors of national income and productivity as well as of improvements in infant and child mortality

* Alaka Malwade Basu, Department of Development Sociology, Cornell University, Ithaca, NY 14853, U.S.A. Email: ab54@cornell.edu 
and reductions in fertility. The extent of these relationships may be contextdependent but the very fact of a relationship seems to be universal. For this reason, as well as for many of the arguments put forward by Lutz and colleagues in a series of recent publications, I support adding education to age and sex in describing and projecting populations.

However, the acknowledgment of positive and probably causal relationships between education and a host of socially and politically desirable indicatorseconomic growth and lowered birth and death rates in particular-is too often extrapolated to make assumptions about the pathways that mediate these relationships. Too easily the assumption is made that it is the radical cognitive development and personal empowerment that education confers which account for the impact of education on development indicators. This assumption kills many birds with one stone. It is politically correct. It reinforces the policy call for greater investments in mass schooling. It allows one to sidestep other, less comfortable, avenues to mass empowerment. And because education is believed to operate in this empowering way, ambiguous hard-to-define parameters like democracy can get reduced to often superficial variables just because they are positively affected by education.

My central point here is that, the relationship with economic growth and improved demographic outcomes notwithstanding, the Enlightenment goals of education are being mistakenly credited with a mediating role in these relationships. Mass primary schooling in developing countries today is being expected to lead to greatly enhanced levels of individual knowledge, empowerment, political awareness and a sense of liberation from the old ignorant ways of doing and thinking. That little of this expectation is actually being met is clear enough. For instance, a burgeoning quantitative and qualitative literature on India documents both the abysmal achievements in the three R's by primaryschooled children, as well as the conspicuous absence of much that can be called empowering or liberating. The policy response to this sorry finding is to seek more and better inputs into school curricula and teacher training as well as increased school supervision, especially (and this is a new big innovation today) by parents.

While all such initiatives are laudable in their intent, it is unlikely that they will make the problem go away. This is hardly surprising. The problem lies in three central features of the education focus today-its 'mass' nature, its contentment with 'primary' or elementary schooling, and its location in the 'developing' world. All three of these doom the attainment of the goals of liberation, autonomy and enlightenment that motivate, at least in principle, the policy of getting all children to complete a few years of schooling. Indeed, these goals are almost bound to be doomed under these three sets of circumstances.

To begin in reverse order, in the resource-crunched developing world there is simply not the money, the skilled manpower nor the technology to invest in the kind of individual oriented, learning focussed and joyous school experience that 
the proponents of mass primary schooling for development are extolling. While it is true that the resource crunch can be mitigated, but only somewhat, by massive national investments and international aid programs, such investments will still not be large enough to be able to keep out of the classroom the social exclusion and social anarchy that characterise poor countries. It is therefore hardly surprising that the typical mass elementary school in a poor country today ends up reproducing and reinforcing the class, caste and gender hierarchies that exist in the larger society from which children are sought to be educated. Several recent evaluation studies confirm the elitism of Third World teachers, their sometimes automatic and often deliberate exclusion of, and discrimination against, children of the 'wrong' class or caste or gender, and the consequent exacerbation of the social and skills gap between the 'best' and the rest. Indeed, recent attempts in countries like India to improve the situation by encouraging and even enforcing greater participation of parents in the educational process seem to even worsen the problem as there are now two generations of the privileged acting to deny this privilege to those that have never had it.

In a parallel way, it is 'mass' or 'universal' primary schooling that fails (that must fail) in meeting the Enlightenment goals of education. Most of the original discourses around these goals and methods of teaching (in Locke and Rousseau for example) focused on an elitist, male-oriented, tutor/governess-led model of education, imparted for non-utilitarian purposes, not for the masses and not for the market. The moral values, intellectual curiosity and pleasure in learning that schooling is supposed to offer require a kind of individualised attention that is difficult enough to uphold in the public classrooms of the industrialised world, as the education literature on primary schools in developed countries continues to point out. In cash-strapped and first-generation learners crowding the typical classroom in poor nations, it is well nigh impossible.

In both settings, it is also well nigh impossible because a six or eight year old child is not receptive to these lessons. The domestic socialisation of the first years of life ill-equip all but the most precocious children to pay attention to and absorb the kind of learning that inculcates a modern sensibility, a thirst for knowledge and an appreciation of abstract reasoning. Such attention and absorption must be preceded by a period of extra-familial socialisation that stresses discipline, concentration and self-control. All these characteristics - discipline, concentration and self-control-are therefore necessary precursors to the liberation and autonomy that subsequent education and schooling can deliver, even if it does not often do so. Such disciplining is what intentionally and otherwise characterises the third plank of the universal education policy goal-universal 'primary' schooling. It is only when policy ambitions rise to efforts to promote universal secondary and post-secondary schooling that the liberating forces of education can begin to take hold. And in reality, again as scores of developing country evaluations attest, even then they do not. 
However, discipline, concentration and self-control are all necessary attributes of a productive workforce and it is not surprising that primary schooling rates correlate so well with national economic growth and productivity in scores of studies, including the examples in Lutz (2009). When they are combined with the respect for and an obedience to authority which primary school also emphasises so much, especially at the early stages of development, such productivity improvements are even bigger. Most employment for workers with primary schooling exploits their ability to follow instructions and to value following instructions, even when (especially when) these instructions require them to take on repetitive assembly-line tasks that throttle curiosity and innovation.

Such discipline, understanding of the notion of clock time and respect for the authority of experts (white coated experts in this case) also go a long way in dealing with the health problems of everyday life in poor countries and it is again not surprising that even low levels of schooling correlate so remarkably with declines in infant and child mortality in the most diverse institutional and political settings; all over the developing world, whatever else primary schools teach or don't teach, they are extremely adept at enforcing discipline and obedience to authority figures.

It is therefore surprising that much of the modern-day development literature on education is so obsessed with cataloguing the empowering effects of education and in turn, the role of such empowerment in rising health and economic growth. Our forefathers, when they pushed for mass primary schooling, were much more clear-eyed in this respect. For example, reviews of historical records for the United States of America conclude that the central acknowledged rationale for mass primary schooling was to 'homogenise' an increasingly heterogeneous population, to propagate standards of public morality, to inculcate work habits consistent with nationalism and the needs of industrial society and to 'reinforce the legitimacy of established authority'. This research is peppered with direct quotes that would make today's spokespersons of the liberal and reflexive enterprise of public education blush deeply.

All this is not to dismiss the goal of universal primary education. If nothing else, universal primary education is essential for the improvements in national health and productivity that are in turn essential for any long-term progress in the quality of life. Such improvements in health and productivity will also hopefully segue into a demand for the higher levels of mass schooling needed to truly empower individuals to think for themselves, to take control of their decisions and to question the status quo. But while waiting for these developments to occur, this essay stresses the need to redefine our educational goals to actively promote and invest in at least mass secondary schooling as well as a strong encouragement to even indulge in post-secondary education in a less inegalitarian way than is presently the case in all the developing world. When that happens, when a college education is no longer the entitlement of the privileged, the words 'education' and 'empowerment' will have a greater right to be employed in the same sentence. 
Finally, I should explain why this is a paper without a real bibliography. First, because the literature on the subject is so large that citing even a fraction of it will take up most of the space allotted to me here. Secondly, much of this literature is forceful and influential enough for its general conclusions to be a part of conventional wisdom now. New discussions seem to focus largely on the operational and technical details of attaining a non-controversial goal of universal primary schooling, raising levels of secondary schooling and closing the gender gap in schooling.

\section{References}

Lutz, W. 2009. "Sola schola et sanitate: human capital as the root cause and priority for international development?" Philosophical Transactions of The Royal Society B 364: 3031-3047.

Lutz, W. 1972. "Volksschule, ein Verbrechen am Kind" (Elementary school: a crime on children). Informationen (Schülerzeitung des Schottengymnasiums in Wien): 2-4 (cited in Lutz 2009). 